\title{
1. A year into the pandemic: shifts, improvisations and impacts for places, people and policy
}

\author{
John R. Bryson, Lauren Andres, Aksel Ersoy \\ and Louise Reardon
}

... the world needs to prepare for pandemics in the same serious way it prepares for war. This preparation includes staging simulations, war games, and preparedness exercises so that we can better understand how diseases will spread and how to deal with responses such as quarantine and communications to minimize panic.

(Bill Gates, 27 April 2018)

The catalyst for this book emerged in late 2019 with the first reports of a 'mystery pneumonia' taking hold in the Chinese city of Wuhan (Horton, 2020). This virus was confirmed by authorities as a new type of Severe Acute Respiratory Syndrome coronavirus (SARS) and given the acronym COVID-19 ('co' for corona, 'vi' for virus and 'd' for disease and '19 for the year in which it was identified). For more than a year the pandemic that followed has transformed the everyday experiences of nearly everyone living on Earth and created significant and often dramatic changes in life trajectories (Žižek, 2020). COVID-19 transformed the relationships between people and place and challenged politicians and officials to engage in rapid and unprecedented policy improvisation intended to save lives and reduce the negative impacts of the pandemic. Some of these transformations will result in permanent alterations and others will be transitory, while the wider impacts will continue to emerge for decades to come. This book is published at a time when COVID-19 is still being experienced and the dust has not yet settled. This is intentional.

This book provides a snapshot of emerging experiences, challenges, and reflections of the outbreak. As all good social science should, it therefore provides a critical analysis of the pandemic to date - as of January 2021 - and aims to start conversations about what lessons can be learnt in the short and medium terms to ensure history does not repeat itself with future pandemics. The focus of this book is on understanding the day-to-day impacts of the COVID-19 pandemic, but also in highlighting the need for effective pandemic contingency plans to be developed. The book has been developed around two 
cross-cutting themes - resilience, and behavioural adaptation and mitigation in the context of rapid improvisation. These are explored through discussions of health and environment, education, governance, economy and business, cities, transport, and spatial planning along with people and community.

COVID-19 rapidly spread across the world with countries responding based on different degrees of preparedness and response. Whereas China and East Asia accustomed to previous pandemic episodes succeeded in controlling the spread of the virus more quickly and efficiently, other countries in Europe and in North and South America for example, very quickly lost control with infection and death rates rising. The mechanisms underpinning the responses remained very similar globally, following general WHO guidelines and involving total and partial lockdowns, social distancing and mask wearing. What differed though was the level of control over people's behaviours and the application of new technologies. As such, COVID-19 led to many different types of impact and these differed by country, place, economic sector, cohort, and time.

Specific sectors, places and people were hit harder. First, cities as dense and compact urban areas became centres of virus transmission. Development models promoting sustainability, urban compactness and public transport revealed their limitations; new challenges emerged for the future of real estate markets linked to new patterns of remote working prompting significant increases in property prices in suburban areas and smaller urban settlements (Salder and Bryson, 2019; Bryson et al., 2021). The mechanisms behind the making of cities and their status as centres for growth and innovation were challenged by new ways of working. Existing approaches to planning urban areas based on increasing density were also challenged as residents engaged in social distancing appreciated the benefits of access to green and open spaces. Urban spaces were converted to temporary uses (Andres, 2020).

Second, healthcare systems were tested highlighting issues of underresourcing and resilience. The emphasis that had been placed on efficiency and productivity had reduced organisational adaptability in response to the crisis. This included significant inequalities between public (universal) and private healthcare systems, and access. As such, while the virus has had an extreme uneven impact on different cohorts, even within the same city, a key factor has been the ability of national healthcare systems to respond to the additional demands placed on service provision and, in particular, beds in intensive care units. An initial difficulty concerned the protection of medical staff with shortages in the availability of personal protection equipment (PPE) for healthcare workers and those working in care homes. The rollout of mass vaccination programmes from 8 December 2020 stretched capacity as healthcare systems had to balance allocating resources to vaccination whilst treating those with COVID-19 and other medical conditions (BBC, 2020). A key impact of 
COVID-19 has been a reduction in medical support for non-COVID-19 related conditions.

Third, people and specifically the most vulnerable were affected significantly. Age, migration and ethnicity, gender, pre-existing health conditions along with socio-economic backgrounds constitute intersectional layers of disadvantage which have been exacerbated with COVID-19 (Anguelovski et al., 2020; Ho and Maddrell, 2020). The most deprived neighbourhoods and cities were the ones hit by the highest rates of transmission and deaths. The most vulnerable living in informal settlements and refugee camps not only struggled with containing the virus but more generally with survival given reductions in informal work opportunities and access to food. This highlighted the intersectional nature of the pandemic, where intersectional burdens revealed COVID-19 related health inequalities.

Fourth, economies both local and national, and the global economy have experienced alterations in consumer demand combined with COVID-19 operational impacts including human resource and supply chain issues. For the first time, governments issued orders closing companies, even whole economic sectors, as one response to reduce virus transmission. The outcome, in many instances, has been recession, a significant increase in unemployment rates, and wider structural changes in investment and consumption trends. The economic impacts of COVID-19 varied by sector and geography. Some sectors have experienced a major increase in demand, for example supermarkets and manufacturers and retailers of webcams, while other sectors have not been able to adjust their activities in response to the imposition of a socially distanced economy. The significant shift towards state-led welfare and business support policies, even if only temporary, will lead to a wider debt crisis and an increase in direct and indirect taxation.

In January 2020, very few people imagined the potential impacts that COVID-19 would have on everyday living on this planet. This is perhaps surprising. Epidemics and pandemics were predicted, and strategies developed in national contingency plans. Nevertheless, no organisation, or country, appears to have been prepared to respond to COVID-19. On the one hand, epidemiologists had been expecting another flu pandemic. Influenza A constantly mutates. These alterations accumulate with the result being that eventually immune defence proteins no longer recognise the mutated version (MacKenzie, 2020). On the other hand, the emergence of SARS-CoV-1 in 2003 was a clear warning of the possibilities of the emergence of another SARS pandemic. Nevertheless, in an analysis of contagious diseases, Kucharski argued that "if you've seen one pandemic, you've seen ... one pandemic" (Kucharski, 2020: 29). Every pandemic is different, making generalisations challenging.

A year on, there are still limited prospects for a return to 'back to normal' and significant uncertainties remain. National governments, organisations and 
individuals must learn from the pandemic and adapt their behaviours and invest in processes, practices, and technologies. We have known for some time, for example, that education is disrupted by pandemic influenza (Santibañez et al., 2009) but that "plans for academic continuity during inter-pandemic periods, including online teaching and assessment, have been recognized as important but are rarely delivered" (Day, 2015: 76). There is a well-developed literature on teaching under emergency conditions with many of the more recent papers focussing on the 2010 New Zealand earthquake (Agnew and Hickson, 2012; Collings et al., 2019; Mackey et al., 2012). However, very few governments or organisations developed effective pandemic contingency plans (although there are exceptions, see Young, 2009). In the UK for example, schools have been closed for long periods during this pandemic. Governments, schools, hospitals, and organisations that rely on people-based interactions should have been pandemic ready; the surprise is that everyone was surprised by COVID- 19 .

With COVID-19, many countries failed to recognise the virus as an immediate, visible, and global threat and to act accordingly. A highly proactive and anticipatory approach was required to limit the initial spread of COVID-19, but too many countries postponed the introduction of measures to control transmission. Such initial indecisions led to chaotic and reactionary responses. In the UK for example, science was used to justify preventive measures and specifically lockdowns were introduced often at short notice. This has led to debates regarding the ways in which scientific contestations are considered in policy, and how evidence should inform practice (see also Cairney, Chapter 22 in this volume).

Policy was developed in response to the spread of COVID-19 and as new variants emerged. This was a process of rapid policy improvisation based on available medical evidence and the application of social and behavioural science intended to persuade people to alter their behaviour. At the same time, policymakers grappled with how to mitigate the impacts on the economy and education (Bavel et al., 2020). Moreover, for the first time, most of the global population was reminded every day of the cycle (and end) of life, leading to a culture of fear of the virus, but most importantly a fear of the 'other' fostering paranoia. This led to the rise of conspiracy theories and more recently social media exchanges and accounts based around a rhetoric of anti-vaccination.

All governments should learn from COVID-19. The danger is that political dialogue, and related policy, focusses on the immediate impacts of COVID-19 and then shifts to emphasising recovery. There needs to be an ongoing discussion regarding developing processes that will lead to rapid identification of possible pandemics focussing on control and containment. This needs to be combined with the development of national contingency plans and related investments. More importantly, people and societies will need to heal and bounce back, and this will involve dealing with many uncertainties and con- 
fusions that emerge in what might be defined as the 'post-truth' era (McIntyre 2018). Behavioural approaches applied to prevent the spread of COVID-19 led to restrictions on freedom, mobilities and rights. This included the temporary withdrawal of rights to proximate education, healthcare, holidays away from home and freedom to wander at will. The unprecedented nature of the pandemic, and the degree of uncertainty, led to compliance by the majority. Nevertheless, attention will need to be given over the longer-term regarding the justification for such restrictions, if they need to be imposed again; this is particularly the case for societies where individual rights and freedoms are prioritised over the collective. Place-based differences in the impacts of COVID-19 on everyday living, and in the management of the pandemic, highlight the importance of understanding the relationship between COVID-19, people, organisations, place, and policy in the context of spatial flows between places. It is these relationships that are explored in this edited collection.

This chapter provides an overarching approach for exploring the relationships between place, people, and policy and living with the COVID-19 pandemic. The second section explores the debate on risk societies, non-calculable uncertainty, and the emergence of Jenga Capitalism. In the third section the relationship between globalisation and disease is explored, and the fourth section outlines national responses to COVID-19 including the emergence of socially distanced economies. The fifth section explores the interrelationships between the pandemic and place, people, and policy more generally. This edited collection is structured around these three 'Ps', but it is worth noting that these are interdependent; people are embedded in places and local and national policy is developed and applied to places. With COVID-19 place mattered as localised outbreaks required the application of localised responses to try to reduce transmission, but also to mediate the negative impacts of COVID-19 on the socio-economy including health, social care, and education. The sixth section considers life after the pandemic including a discussion of the impacts on national policy including fiscal policy. In the seventh section, the structure of this edited collection is outlined.

\section{PANDEMICS, RISK SOCIETY AND THE EMERGENCE OF JENGA CAPITALISM}

There are hundreds of different types of coronaviruses; these viruses are common in animals including bats, camels, and cats. Before the identification of COVID-19, six types of coronavirus had been known to infect humans through cross-species transfer from animal hosts to humans. The emergence of COVID-19 represented a seventh. Four of the six coronaviruses that had crossed over into humans resulted in mild to moderate symptoms. Two, however, came with high mortality rates and were labelled as Severe 
Acute Respiratory Syndrome coronavirus (SARS): Middle-East Respiratory Syndrome coronavirus (MERS-CoV) and SARS-CoV-1. The latter emerged in China in 2002-03 and spread to 37 countries. This version had a mortality rate of $10 \%$. This form of SARS was contained having initially spread out of control in China and some lessons (particularly towards preventive mechanisms) were learnt. Companies involved in configuring global supply chains, or global production networks, failed to learn from the SARS pandemic even though strategies to enhance supply chain resilience had been identified (Tan and Enderwick, 2006; Bryson and Vanchan, 2020).

As one policy response to SARS-CoV-1, the Chinese government developed a best practice contagious disease reporting system. This Contagious Disease National Direct Reporting System was installed in every Chinese hospital. Doctors were required to enter details of their diagnosis into this system when they encountered specified infectious diseases including diseases of unknown origin. This system was designed to ensure that a disease outbreak would be rapidly identified by the national Chinese Centre for Disease Control and Prevention (CDC). An appropriate immediate response to control the output could then be implemented nationally. Unfortunately, immediate action regarding COVID-19 failed to occur. COVID-19 appears to have been identified in Wuhan in November 2019 as an unusual form of pneumonia and doctors were instructed "not to report such cases to the automated alert system" but only to "local health officers, who were reluctant to pass on bad news" (MacKenzie, 2020: 23). To MacKenzie, this "was as if someone took the batteries out of the smoke alarm that sounded too many false alarms - so it missed a real fire" (MacKenzie, 2020: 23). Beijing only became aware of the problem on 30 December after Wuhan doctors leaked reports online. This leak came from Li Wenliang, a Chinese ophthalmologist based in Wuhan who privately alerted medical friends and colleagues via WeChat about the existence of a new form of SARS. His posts were leaked, and he was "detained, questioned and admonished for 'rumour-mongering'. Li was forced to sign a statement confirming that he would stop spreading these rumours" (Horton, 2020: 2-3). COVID-19 might perhaps have been contained if appropriate action had been taken in November 2019 or early in December. There is no way of knowing and we will probably never know. According to Horton, "those four letters S-A-R-S - struck fear and not a little panic into Chinese health officials when the news arrived in Beijing" (Horton, 2020: 2). On 31 December 2019, China reported the outbreak to the World Health Organization (WHO), but by then it was too late; COVID-19 had already spread widely.

COVID-19 and climate change have highlighted that everyone living on this planet is exposed to risks that are beyond their control. All societies come with benefits and risks. In 1986, Ulrich Beck highlighted that the nature of these risks had changed with the emergence of a new type of modernity. The 
conventional approach to risk was based on calculable uncertainty, but to Beck a new form of risk had emerged based on non-calculable uncertainty (Sørensen, 2002). This new form of uncertainty was paradoxical as solutions must be found "to problems that we are often unable to articulate" (Sørensen, 2018: 11). These include extremely complex problems, for example, structural inequalities, uneven development, and climate change. There is a strange paradox here in that "risk might in fact be increasing due to technology, science and industrialism rather than being abated by scientific and technological progress" (Jarvis, 2007: 23). One of the characteristics of the new risk society identified by both Beck (1992) and Giddens (1998) was the relationship between new forms of risk and human activity rather than non-human activity including natural disasters. In a risk society, according to Giddens, there are external risks and manufactured risks with the latter being the result of human interventions (Giddens, 1999).

There are many different literatures that explore new forms of risk. The management literature explored risk management in response to SARS-CoV-1. This analysis highlighted that infectious epidemics are not a new phenomenon, but that SARS had a greater impact on international business compared to earlier epidemic/pandemic events. This was "largely due to the fact that countries and economies, are now more interconnected than before, allowing for easy transmission of a virus like SARS" and that "SARS is indicative of a new kind of uncertainty" requiring new approaches to the management of risk (Tan and Enderwick, 2006: 516). This analysis did not engage with the debate on the emergence of a risk society or the work of Charles Perrow. Perrow made an important contribution to understanding the emergence of new forms of risk related to the complexity of tightly coupled systems (1984; 2007). His approach is based on the identification of two factors that enhance system susceptibility to risk. On the one hand, risk emerges in the ways in which different parts of a system interact with one another. Some systems are linear, meaning that any failure is obvious, while other systems are much more complex, meaning that their parts may interact in unexpected ways. Much that occurs in complex systems is hidden. The second factor in Perrow's theory is based on how much slack exists in a system. This concept of slack comes from the engineering literature on tight coupling or system optimisation. In this account of engineering systems, tight coupling is associated with limited slack, or buffering, existing between different parts of the system. The opposite of tight coupling is loose coupling in which slack exists in a system with the result being that any failure of one part of a system can be covered by the slack that exists elsewhere. Perrow applied this approach to understanding high risk technologies including nuclear plants, but also to the AIDS global epidemic (Perrow and Guillén, 1990). 
The concept of organisational slack also emerged in the literature on the theory of the firm. In 1963, Cyert and March published what has become a classic work on organisational theory (2001). This analysis explored the contribution organisational slack makes to organisations. Thus, "when the environment becomes less favourable, organisational slack represents a cushion" and "absorbs a substantial share of the potential variability in the firm's environment" (2001: 43). In this analysis, organisational slack functions by stabilising the organisation. The problem is that a focus on efficiency, value for money, performance, system optimisation and productivity has tended to identify organisational slack as reflecting inefficiency and poorly managed systems. Organisational slack is, therefore, identified and removed, and this process increases rather than reduces risk. Productivity and growth have been central pillars in economic development policy (Bryson et al., 2020b). It is perhaps ironic that the drive to enhance productivity also increases societal and organisational risks.

COVID-19 has highlighted that globalisation, combined with technological convergence, has led to new forms of non-calculable uncertainty. This suggests that the risk society debate needs to be revisited. System convergence, optimisation and increasing complexity, combined with enhanced global connectivity, is perhaps best described as representing a new epoch. One aspect of system convergence is the emergence of a cyber-energy plexus based on the digitalisation of socio-economic processes that support everyday living (Bryson et al., 2020b; Bryson et al., 2021). This new epoch is not the Anthropocene as non-human agents continue to have a significant impact on the planet and on humanity; COVID-19 is an excellent example of the power of non-human agents to disrupt human activity. This new epoch represents the emergence of a new form of risk society that is perhaps best described as the epoch of Jenga Capitalism (Bryson, 2021). Jenga is a board game in which players take turns to remove one block at a time from a tower constructed of 54 wooden blocks. Each block that is removed is placed on the top of the structure and the structure becomes progressively less stable. Globalisation has resulted in system convergence combined with enhanced connectivity. The outcome is similar to a game of Jenga. Eventually, in a Jenga game removing one block, and replacing it, will result in the complete collapse of the structure. COVID-19 is one Jenga Capitalism event. Other pandemics will follow given the increase in human population, combined with increased density, and place-based convergence. There have been other indications of Jenga Capitalism. These include SARS in 2003, the 2010 Canterbury earthquake, New Zealand, the Japanese earthquake of 2011 that disrupted production across the planet, and the 2010 volcanic eruption of Eyjafjallajökull in Iceland. The latter disrupted air travel across western and northern Europe and across the Atlantic for six days. 
Climate change is included in Jenga Capitalism and will result in systemic disruption. The difference between a pandemic and climate change is one of duration and impact. Compared to climate change, a pandemic is of short duration and has limited impacts. The primary challenge facing humanity is not founded on pandemics but on climate change. Climate change will contribute to the spread of pathogens that have the potential to cause pandemics.

\section{GLOBALISATION AND DISEASE}

There are more people living on this planet than ever before. There has been an increase in population density combined with an extension of human activity into more marginal areas. One outcome is that there is more direct and indirect contact between people and wildlife. This provides more opportunities for pathogens to jump from wildlife to humans. Thus, COVID-19 according to MacKenzie "started with one jump of a bat virus to one or a few humans. Then that was followed by millions of transmissions among us. That second thing the transmission of virus between humans - is the problem" (2020: 110). One solution is to develop surveillance systems to identify this second moment of transmission. An alternative solution is to limit contact between humans and wildlife. The increase in human population and density contributes to Jenga Capitalism.

The rapid spread of COVID-19 highlights one of the risks related to globalisation. Globalisation comes with many benefits, but there are two important risks. On the one hand, COVID-19 has highlighted that disease anywhere has the potential to become disease everywhere. The only way of preventing this is by the immediate identification of a disease that has the potential to become a pandemic and to institute appropriate and prompt containment actions. This would require global cooperation based on effective national reporting systems. This type of global cooperation is perhaps unlikely to develop due to differences in political regimes along with geopolitical and global competitiveness factors. On the other hand, globalisation is also associated with carbon emissions and environmental pollution, constructed upon freedom of mobilities and circulation. Globalisation requires increasing co-ordination including investment in innovations intended to reduce the spread of disease and to decarbonise global value chains and everyday living. Such actions can and should go together with addressing the climate change crisis (Watts et al., 2020).

Human life is precarious. Many health specialists became aware of COVID-19 via ProMed or the PROgram for Monitoring Emerging Diseases of the International Society for Infectious Diseases (ProMed, 2021). This is the primary online system for reporting new and emergent infectious diseases. ProMed is run by a not-for-profit organisation and relies on grants, donations, 
and volunteers. It is perhaps surprising that one of the most critical of global infrastructures is based on volunteer inputs. A global pandemic had been predicted and countries had been developing pandemic plans since the outbreak of H5N1 bird flu in 2004. Yet no country was prepared for this pandemic and for how quickly it spread globally. The primary lesson that must be learnt from COVID-19 is that all countries must develop effective pandemic preparedness plans, and this includes investment in identification and reporting systems. This also includes a considerable increase in cooperation between countries. There will be other pandemics; strategies will need to be developed by governments and global organisations that can be applied rapidly and that are intended to prevent a disease outbreak from becoming a pandemic.

Perhaps the other surprising thing about COVID-19 is that this is the first virus in recent times that has rippled across the world impacting on the everyday life experiences of the whole planet's population. The history of humanity is one of epidemics and pandemics (see Centers for Disease Control and Prevention, 2020, for details of earlier outbreaks). The Black Death (1346-53) travelled from Asia to Europe and altered the course of European history. Labour shortages led to better working conditions, but also contributed to technological innovation. Increased global connectivity contributed to the rapid spread of the influenza virus (1889-90). It took a few months for this virus to span the globe resulting in over a million deaths. The 1918-20 Spanish Flu pandemic infected 500m and around 100m died. Between 1957 and 1958, Asian Flu (H2N2) spread from East Asia resulting in 1.1m deaths with 116,000 in the US. In 1981, human immunodeficiency virus (HIV) that causes AIDS was first identified. This virus appears to have resulted from cross-species transfer from chimpanzees and has been responsible for over $35 \mathrm{~m}$ deaths. The Swine Flu pandemic (2009-10) originated in Mexico in the spring of 2009 and killed between 151,700 and 575,400 people. Between 2014 and 2016, Ebola spread across West Africa killing 11,325. No cure has been developed. In 2015, the Zika epidemic emerged in South and Central America; this is still ongoing. An important point to consider is that COVID-19 impacted on countries and populations which considered themselves to be relatively protected against pandemic risks.

Forecasting the future is always something that should be avoided. Nevertheless, there is one certainty, and this is that there will be more pandemics combined with "manufactured risks" (Giddens, 1999). Epidemiologists had been expecting another flu pandemic, but national governments were not prepared. According to MacKenzie "if we're not ready for the pandemic we can see coming, how can we be ready for the ones we don't?" (2020: 140). The one thing that is now known is that "anticipation and prevention of infectious diseases are possible, necessary and ultimately cost-effective" (Lederberg et al., 1992: v). However, the same source of analysis (the US Institute of 
Medicine) highlights that emerging disease problems "are largely the result of complacency" (Lederberg et al., 1992: 138). The detrimental impacts of COVID-19 across all facets of society have demonstrated that prevention is cost-effective. The direct and indirect costs of the COVID-19 pandemic will come to trillions of dollars/pounds/euros/renminbi. In 2016, the U.S. National Academy of Medicine calculated that:

... the annualized expected loss from potential pandemics is more than $\$ 60$ billion. Against this, we propose incremental spending of about $\$ 4.5$ billion per year a fraction of what we spend on other risks to humankind. Framed as a risk to human security, this is a compelling investment. Framed as a risk to economic growth and stability, it is equally convincing. (GHRF Commission, 2016: 1-2)

There is no question that humankind must develop approaches to identifying disease outbreaks that have the potential to become pandemics. It must be recognised that pandemics are a public health issue as well as a political, economic and security challenge; effective national and global control strategies must be developed.

\section{THE EMERGENCE OF SOCIALLY DISTANCED ECONOMIES AND SOCIETIES}

A pandemic is an infectious disease that has spread across a large region or multiple continents. The nature of this spread depends on the disease and its ability to survive and reproduce. Moreover, diseases mutate, and this includes cross-species transmission resulting in immune defence proteins, or antibodies, perhaps not identifying a pathogen. With a virus there is an "arms race between the virus and the host" (MacKenzie, 2020: 198). Vaccination, or previous infection, provides individuals with direct protection against disease. Herd immunity develops when a percentage of a population has become immune to an infection and this then reduces opportunities for transmission. With an epidemic or pandemic, for example with COVID-19, there is no herd immunity. This either must develop via vaccination or by individuals developing antibodies in response to infection. The implication is that governments need to develop strategies to minimise transmission. Initially, the focus must be on controlling and limiting the spread of any outbreak. Once an outbreak has become a pandemic then the policy focus shifts to limiting transmission through the rapid imposition of a 'socially distanced', or physically distanced, society and economy.

With COVID-19, the WHO highlighted that there were different levels of risk related to the transmission of COVID-19. In one of the first books pub- 
lished on COVID-19, Richard Horton, Editor-in-Chief of The Lancet, noted that:

COVID-19 is a pandemic of paradoxes. Most of those who became infected with this new coronavirus suffered only mild disease, perhaps not easily shaken off, yet shaken off nevertheless. But a substantial number - perhaps as many as one in five - developed a much more severe illness, often requiring intensive care and mechanical ventilation. For far too many, COVID-19 meant that death was their destiny. (Horton, 2020: vii)

In this context, geography, and place matter. The WHO (2020) highlighted the importance of avoiding the three 'Cs':

- Crowded places with many people nearby.

- Close-contact settings especially where people have close-range conversations.

- Confined and enclosed spaces with poor ventilation.

The risk of COVID-19 transmission was highest in places where these three factors overlapped. To stay safe, people were progressively advised to wear a face mask in public places, maintain a distance of at least $2 \mathrm{~m}$ from other people, reduce contact with others, frequently wash their hands and to avoid the three 'Cs'. During periods of enforced lockdown different local, regional, and national restrictions were introduced by governments to minimise transmission. These included closing non-essential retail and hospitality services and encouraging employers to adopt a work-from-home (WFH) approach.

These preventive strategies, however, resulted in the development of a two-tier labour market. On the one hand, there are those jobs that could be facilitated through WFH. This led to rapid improvisation by companies and employees. From a management point of view, it included the creation of alternative socially distanced social events, for example, virtual coffee sessions and virtual Christmas parties. The rapid shift to remote working also enhanced opportunities for cyber-attacks. Employees working from home were sent emails pretending to come from their employer's service desks requesting them to reset their log-in passwords. Some were tricked into downloading ransomware software. Employees were also sent WhatsApp messages purporting to come from line managers requesting them to set up money transfers. An additional risk occurred when WFH employees printed sensitive documents and then placed them in their domestic waste without shredding. For employees, it meant developing workspaces at home. During periods of lockdown when schools were closed it also meant balancing work commitments with family responsibilities. There were great inequalities here related to household composition combined with the size and location of the residential unit. 
On the other hand, there were occupations in which WFH was impossible. These included 'keyworkers' or essential workers employed in healthcare, police, military, and teaching, but also others working in roles not previously considered in this way, including those working in agriculture, grocery retailing, logistics and in the provision of infrastructure-related services including the provision of water, electricity, and broadband. These keyworkers were given special dispensation to send their children to nurseries and schools, and in turn this highlighted the roles required to facilitate everyday living. For some employees, the impact of COVID-19 meant unemployment, with redundancies derived from lockdown restrictions which challenged the viability of businesses in non-essential retailing, hospitality, and construction. One response was the introduction of furlough schemes in which governments took over responsibility for paying the salaries of employees in businesses that were forced to close to minimise COVID-19 transmission.

Strict lockdown measures in turn had significant unintended impacts on the most vulnerable in society, for example, causing those facing domestic violence to remain in danger and children to experience acute food poverty. The most vulnerable children were disadvantaged as schools closed and classroom-based teaching was replaced with online provision. Children without access to computers, broadband and a room conducive to learning were disadvantaged. COVID-19 related educational disadvantage reinforced existing disadvantages related to intersectionality. Those living in informal settlements, including refugee encampments, had to balance attempts to control transmission with limited wash facilities combined with a reduction in opportunities to engage in the informal economy. In March 2020, India instigated the world's largest lockdown involving 1.3 billion people who were in lockdown for 21 days (The Lancet, 2020). This was especially challenging for an under-resourced democracy. On 26 March 2020, the Indian government announced a $\$ 22 \mathrm{bn}$ package of support for the country's most vulnerable including cash and free food. One difficulty was in managing migrant workers who were working in India's major cities (Iyengar and Jain, 2020). These workers lived in informal settlements and relied on daily wages from working on construction sites and in factories. These are precarious jobs; lockdown meant unemployment and an inability to afford food. The only option for many was to return to their villages, with this subsequent migration enhancing transmission of COVID-19.

COVID-19 has forced individuals, companies and governments to engage in disruptive innovation. WFH has been technically possible for most of this century. Employers have been reluctant to widely adopt WFH preferring to focus on the traditional approach to office-based working. COVID-19 changed this. Offices were emptied and employers were forced to develop innovative solutions to task delivery based on homeworking. The outcome of 
this forced improvisation led to a temporary or maybe more permanent shift in company work cultures. Companies realised that tasks could be completed, and productivity maintained, and often enhanced, with a WFH approach. For employees, WFH resulted in saving the time and costs related to commuting (including tickets, or fuel, food and drink). The forced adoption of WFH also altered consumer expenditure with negative impacts for companies reliant on commuting-related custom. It also highlighted differences between countries in the legal perception of risks and how these are applied to human resources and safety regulations. In the US and UK for example, physical return to work was subjected to strict health and safety checks and manager's approval, with a view to protecting firms against any form of future litigation.

A key question that needs to be considered is related to the longer-term duration of any COVID-19 related adaptations introduced by employers. The outcome will perhaps be permanent changes in the nature of work, in economic sectors and in the configuration of global production networks (Bryson and Vanchan, 2020). Retailers were forced to invest in their online stores and related delivery systems. Retailers without an online presence rapidly had to invest in developing one or to identify local solutions to distributing products to customers. However, it is likely that centrally located offices will continue to exist. Employers will develop blended or hybrid approaches to work with employees engaged in WFH combined with office-based work. All this must be placed in the context of the application of artificial intelligence (AI) to tasks and the substitution of labour with machines (Gardner and Bryson, 2020; Bryson et al., 2020b).

All this has major implications for the structure of cities, their local economies and for their future development. Any longer-term adjustments will reflect the interplay between people, policy, place, culture, and variety of capitalism (Hall and Thelen, 2008). In some settings, companies may require fewer on-site workstations with reductions in the size of their buildings. Many of these buildings are owned by pension funds and any reduction in demand may impact on rental levels and investment yields. A reduction in the number and length of commuting trips may have a positive impact on $\mathrm{CO}_{2}$ emissions; changing work patterns may lead to reduced congestion, enhancing air quality. These alterations will lead to a reduction in consumer demand for retail and hospitality services (restaurants and coffee shops) located in office districts. It may be that the location of this demand shifts towards areas with concentrations of residential units. Moreover, the potential for longer-term changes to consumer, retail and employer behaviour is an important factor in determining the impacts that COVID-19 will have on the economy and on those companies that will win and lose from these alterations. A review of 2020 alterations in retail trends (Stedman, 2021) for example, identified an increase in the sale of leisurewear and reduced demand for formal wear. It also included a reduction 
in demand for lipsticks and an increase in demand for eye makeup and skin care products. A key issue will be the duration of these alterations in consumer behaviour. Perhaps the most significant is the impact that COVID-19 lockdowns have had on forcing consumers and employers to embrace online retailing and working from home.

Another major shift that characterised the year 2020 is associated with the emergence of a new vocabulary of Zoom, (Microsoft) Teams, Skype, Google Meet and WeChat. The WFH and stay-at-home measures (including online schooling) introduced by countries as one response to reduce transmission of COVID-19 led to the rapid uptake of videoconferencing for all ages from reception children (aged 4 to 5 years old) to those aged over 80 . Communicating via a technological interface has become an important feature of everyday living which can be traced back to the widespread adoption of the telephone. Prior to COVID-19, videoconferencing was an occasional tool used by people and businesses for mainly work purposes. With COVID-19 this tool became an everyday essential used to support business, governance, education, and day-to-day living.

The ongoing 'zoomification' of work and society has led to some novel forms of improvisation. Churches improvised with the development of online services and the application of teleconferencing and instant messaging to support pastoral care (Bryson et al., 2020a). This included, for example, the United Dioceses of Dublin and Glendalough (Ireland) developing an online Service of Nine Lessons and Carols that was produced by a collaboration of over 100 singers from 30 parishes across Ireland. Musicians and actors involved in the provision of live performances had to cope with the closure of concert halls and theatres. This impacted on both performers and those involved in backstage operations. The Old Vic Theatre, London, introduced the Old Vic: In Camera, as an attempt to substitute for revenue lost from ticket sales. This was a new artistic initiative of ticketed socially distanced performances streamed live from the Old Vic stage with the empty auditorium as a backdrop. In December 2020, the Old Vic live streamed Matthew Warchus' production of The Christmas Carol. These performances were sold out. The production was reviewed in both the UK and American press. In Russia, the Bolshoi Theatre was closed from 17 March to 10 April 2020 and streamed past performances online. Theatre Nisha, Chennai, India, during lockdown, introduced play reading sessions via Zoom every evening.

Online church services, and the introduction of ticketed accessed live streamed performances, transformed the geography of access. Participants from across the globe could select and participate in these services and performances. This represents a major innovation that enhances the geographic reach of churches, concert halls and theatres. However, even if some cultural institutions managed to improvise and secure new ways to generate income, many 
others struggled to survive and sustain their activities. The cultural sector was one of the most negatively affected by the pandemic.

The effects of COVID-19 flowed through the world's health, educational, cultural, financial, commercial, and sporting institutions. In the world of sports, competitions and matches were cancelled or postponed and the effects rippled across broadcasters and businesses that are linked to the sports ecosystem. The 2020 Tokyo Olympics were postponed to 2021. Cinemas had to close during lockdowns, and this resulted in major problems both for cinema operators and film studios. On 16 March 2020, Universal announced that its very recent film releases would be available to consumers at home via on-demand providers. This was a break with tradition; the convention was that a movie would only be available in cinemas for between 70 and 90 days from the initial release date. After this period had concluded, there would be a second wave of sales linked to consumers watching from home. The other studios (Warner Brothers, Disney, and Sony) copied Universal. The result being that in 2020 most major movie releases were available on-demand from home and some movies were never shown in cinemas. The danger is that this might have a long-term impact on undermining the business models of cinema operators.

\section{PLACE, PEOPLE AND POLICY}

It is important to appreciate the complex interrelationships between COVID-19 impacts and place, people, and policy. Different cultures and varieties of capitalism, or governance regimes, responded to COVID-19 related policy interventions in different ways. This reflects the variegated nature of the relationship between place, people, and policy. Different outcomes, or the effectiveness of policy responses, cannot be simply explained by different policy regimes and approaches to governance.

The approach adopted by China reflected the ability of a one-party state to regulate human behaviour, supported by technologies that were applied to monitor and control individual movement, interactions, and compliance. In China, a centralised database connected an individual's COVID-19 test results with their 'health kit', a mini program embedded within the WeChat app. Residents wanting to enter their own apartment building in Beijing during a high COVID-19 alert, for example, would need to scan the track-and-trace code with their mobile phone and complete a form whilst having their temperature taken (Murray, 2021). When pupils tested positive in a Chinese school then all pupils and teaching staff were quarantined in 17 hotels and their families and close contacts placed under observation. In China, localised lockdown involved cities entering "wartime mode" (Murray, 2021); all public places were closed, all residents were issued with stay-at-home orders and there was mandatory mass testing. Since March 2020, inbound travel has been severely 
restricted across China and there was a compulsory centralised 14-day quarantine for anyone entering China and, in some places, this was extended to 28 days. These stringent measures were largely successful. Beyond those areas that were in 'wartime mode' shops, restaurants, factories, offices, schools, and universities remained open. Wuhan was in wartime mode from January to April 2020, and by 2021 this city was declaring itself to be the safest place in the world. The key to China's containment of COVID-19 after December 2019 has been based on a zero-tolerance approach. This approach was facilitated by the activities of neighbourhood committee representatives that enforced government policy locally; noncompliance comes with the risk of police detention. Nevertheless, cultural differences played an important role in China's ability to enforce a zero-tolerance approach. Confucianism is part of the explanation as this emphasises respect for rulers, family, and social cohesion. This underpins the collective nature of Chinese society which includes a focus on group affiliation and the importance of an individual subjugating their interests for the good of the wider group (Stipek, 1998; Gambrel and Cianci, 2003; Mo, 2007). Other cultures that emphasise the rights of the individual experienced a very different COVID-19 response.

Confirmed cases of COVID-19 infection and death by country highlight major differences (Table 1.1). These, in part, reflect geography and the ability to control borders, culture, existing control mechanisms and differences in data collection and in the definitions applied to categorise COVID-19 cases and deaths. For the UK, for example, there has been an ongoing political and media debate regarding the political and policy response to COVID-19. COVID-19 was politicised. Nevertheless, it is important to appreciate that there are two factors that contribute to the level of COVID-19 confirmed cases and deaths in the UK. First, London is one of the most important global cities that plays a key role in regulating global flows of finance. The role London plays as a global hub exposes the wider UK population to enhanced risks of exposure to disease that is transferred from one place to another. A study of the UK COVID-19 experience during early 2020 identified that the "UK's first epidemic wave resulted from the concurrent growth of many hundreds of independently-introduced transmission lineages" (du Plessis et al., 2021). The extent and diversity of these transmission events highlighted the role that London and the UK plays in the global economy. Second, the UK is one of the most densely populated countries with a relatively high population. In addition, commuting patterns link towns and cities together with London, for example, having an extensive travel to work area. This means that visitors to London and the South East were able to transmit COVID-19 to UK residents who then distributed the virus around the UK. 
Table 1.1 COVID-19 cases and deaths, by 1 February 2021

\begin{tabular}{|c|c|c|c|c|}
\hline Country & $\begin{array}{r}\text { Confirmed } \\
\text { Cases }\end{array}$ & Deaths & $\begin{array}{l}\text { Case- } \\
\text { Fatality }\end{array}$ & Death/100k population \\
\hline Belgium & 710,153 & 21,092 & $3.0 \%$ & 184.66 \\
\hline United Kingdom & $3,828,183$ & 106,367 & $2.8 \%$ & 159.98 \\
\hline Czechia & 984,774 & 16,308 & $1.7 \%$ & 153.48 \\
\hline Italy & $2,553,032$ & 88,516 & $3.5 \%$ & 146.47 \\
\hline United States & $26,185,355$ & 441,319 & $1.7 \%$ & 134.89 \\
\hline Peru & $1,138,239$ & 41,026 & $3.6 \%$ & 128.25 \\
\hline Mexico & $1,864,260$ & 158,536 & $8.5 \%$ & 125.63 \\
\hline Spain & $2,743,119$ & 58,319 & $2.1 \%$ & 124.82 \\
\hline Croatia & 232,426 & 5,027 & $2.2 \%$ & 122.93 \\
\hline Sweden & 566,957 & 11,591 & $2.0 \%$ & 113.83 \\
\hline France & $3,255,920$ & 76,201 & $2.3 \%$ & 113.75 \\
\hline Switzerland & 521,320 & 9,381 & $1.8 \%$ & 110.15 \\
\hline Argentina & $1,927,239$ & 47,974 & $2.5 \%$ & 107.82 \\
\hline Brazil & $9,204,731$ & 224,504 & $2.4 \%$ & 107.18 \\
\hline Chile & 727,109 & 18,452 & $2.5 \%$ & 98.52 \\
\hline Poland & $1,513,385$ & 37,180 & $2.5 \%$ & 97.90 \\
\hline Romania & 728,743 & 18,335 & $2.5 \%$ & 94.15 \\
\hline Austria & 414,398 & 7,721 & $1.9 \%$ & 87.27 \\
\hline Slovakia & 249,913 & 4,642 & $1.9 \%$ & 85.22 \\
\hline Netherlands & 992,075 & 14,108 & $1.4 \%$ & 81.88 \\
\hline Kosovo & 60,218 & 1,498 & $2.5 \%$ & 81.18 \\
\hline South Africa & $1,453,761$ & 44,164 & $3.0 \%$ & 76.44 \\
\hline Iran & $1,417,999$ & 57,959 & $4.1 \%$ & 70.85 \\
\hline Germany & $2,225,659$ & 57,163 & $2.6 \%$ & 68.93 \\
\hline Ireland & 196,547 & 3,307 & $1.7 \%$ & 68.14 \\
\hline Malta & 17,903 & 267 & $1.5 \%$ & 55.22 \\
\hline Greece & 156,957 & 5,796 & $3.7 \%$ & 54.03 \\
\hline Israel & 643,435 & 4,796 & $0.7 \%$ & 53.99 \\
\hline Canada & 782,467 & 20,005 & $2.6 \%$ & 53.98 \\
\hline Russia & $3,808,348$ & 72,029 & $1.9 \%$ & 49.85 \\
\hline Albania & 78,127 & 1,380 & $1.8 \%$ & 48.14 \\
\hline Bahamas & 8,174 & 176 & $2.2 \%$ & 45.64 \\
\hline Lebanon & 301,052 & 3,082 & $1.0 \%$ & 45.00 \\
\hline Honduras & 147,843 & 3,610 & $2.4 \%$ & 37.65 \\
\hline
\end{tabular}




\begin{tabular}{|c|c|c|c|c|}
\hline Country & $\begin{array}{r}\text { Confirmed } \\
\text { Cases }\end{array}$ & Deaths & $\begin{array}{r}\text { Case- } \\
\text { Fatality }\end{array}$ & Death/100k population \\
\hline Denmark & 199,156 & 2,126 & $1.1 \%$ & 36.67 \\
\hline Iraq & 619,636 & 13,047 & $2.1 \%$ & 33.95 \\
\hline Turkey & $2,477,463$ & 25,993 & $1.0 \%$ & 31.50 \\
\hline Dominican & 214,060 & 2,666 & $1.2 \%$ & 25.09 \\
\hline \multicolumn{5}{|l|}{ Republic } \\
\hline Morocco & 471,157 & 8,275 & $1.8 \%$ & 22.97 \\
\hline Saudi Arabia & 368,074 & 6,375 & $1.7 \%$ & 18.92 \\
\hline Cyprus & 30,876 & 199 & $0.6 \%$ & 16.73 \\
\hline Jamaica & 15,653 & 350 & $2.2 \%$ & 11.93 \\
\hline India & $10,757,610$ & 154,392 & $1.4 \%$ & 11.41 \\
\hline Indonesia & $1,078,314$ & 29,998 & $2.8 \%$ & 11.21 \\
\hline Norway & 62,966 & 564 & $0.9 \%$ & 10.61 \\
\hline Maldives & 15,841 & 52 & $0.3 \%$ & 10.08 \\
\hline Philippines & 525,618 & 10,749 & $2.0 \%$ & 10.08 \\
\hline Mauritania & 16,635 & 422 & $2.5 \%$ & 9.58 \\
\hline United Arab & 303,609 & 850 & $0.3 \%$ & 8.83 \\
\hline \multicolumn{5}{|l|}{ Emirates } \\
\hline Zimbabwe & 33,388 & 1,217 & $3.6 \%$ & 8.43 \\
\hline Iceland & 6,002 & 29 & $0.5 \%$ & 8.20 \\
\hline Saint Lucia & 1,195 & 13 & $1.1 \%$ & 7.15 \\
\hline Afghanistan & 55,023 & 2,400 & $4.4 \%$ & 6.46 \\
\hline Pakistan & 546,428 & 11,683 & $2.1 \%$ & 5.51 \\
\hline Bangladesh & 535,139 & 8,127 & $1.5 \%$ & 5.04 \\
\hline Japan & 390,166 & 5,753 & $1.5 \%$ & 4.55 \\
\hline Zambia & 54,217 & 763 & $1.4 \%$ & 4.40 \\
\hline Venezuela & 126,927 & 1,189 & $0.9 \%$ & 4.12 \\
\hline Australia & 28,818 & 909 & $3.2 \%$ & 3.64 \\
\hline Kenya & 100,773 & 1,763 & $1.7 \%$ & 3.43 \\
\hline South Korea & 78,508 & 1,425 & $1.8 \%$ & 2.76 \\
\hline Malaysia & 214,959 & 760 & $0.4 \%$ & 2.41 \\
\hline Haiti & 11,533 & 245 & $2.1 \%$ & 2.20 \\
\hline Yemen & 2,121 & 615 & $29.0 \%$ & 2.16 \\
\hline Ethiopia & 137,650 & 2,093 & $1.5 \%$ & 1.92 \\
\hline Cuba & 26,686 & 214 & $0.8 \%$ & 1.89 \\
\hline Sri Lanka & 64,157 & 316 & $0.5 \%$ & 1.46 \\
\hline Ghana & 67,010 & 416 & $0.6 \%$ & 1.40 \\
\hline
\end{tabular}




\begin{tabular}{lrrrr}
\hline Country & $\begin{array}{r}\text { Confirmed } \\
\text { Cases }\end{array}$ & Deaths & $\begin{array}{c}\text { Case- } \\
\text { Fatality }\end{array}$ & Death/100k population \\
\hline Somalia & 4,784 & 130 & $2.7 \%$ & 0.87 \\
Nigeria & 131,242 & 1,586 & $1.2 \%$ & 0.81 \\
Mauritius & 569 & 10 & $1.8 \%$ & 0.79 \\
Brunei & 180 & 3 & $1.7 \%$ & 0.70 \\
Singapore & 59,536 & 29 & $0.0 \%$ & 0.51 \\
New Zealand & 2,304 & 25 & $1.1 \%$ & 0.51 \\
China & 100,063 & 4,817 & $4.8 \%$ & 0.35 \\
Thailand & 19,618 & 77 & $0.4 \%$ & 0.11 \\
Vietnam & 1,817 & 35 & $1.9 \%$ & 0.04 \\
Taiwan & 911 & 8 & $0.9 \%$ & 0.03 \\
\hline
\end{tabular}

Source: Adapted from Johns Hopkins (2021).

In countries like the UK, US, France, the Netherlands, and Germany coronavirus-denial movements emerged. On 1 August 2020, a mass demonstration of over 20,000 coronavirus deniers occurred in Berlin. These protestors accused the German government and press of lying about the pandemic. Very few of these protestors wore face masks and engaged in social distancing. Linked to this has been the emergence in Germany of the "Querdenker" or lateral thinkers' movement. This movement has seen tens of thousands of people gather to support the fundamental rights to freedom of opinion, expression and assembly that are enshrined in the German Constitution. These types of protest reflect tensions between the initial fear of being infected with COVID-19 compared with concerns that developed about the economic consequences, including educational impacts, of extended lockdowns. American anti-lockdown protests commenced in mid-April 2020 with protests in several states. By 1 May 2020, there had been demonstrations against State government-imposed lockdowns and restrictions on personal liberty in more than half of US states. The more recent events leading to the storming of the US Capitol on 6 January 2021 by unmasked mobs highlighted the dangerous recuperations of health conspiracies in far-right political agendas.

COVID-19 has highlighted the precariousness of everyday living. An invisible non-living microbe has altered the course of human history. It will mark generations to come and will for sure enter history books. Some individuals, and specific age ranges (typically teenagers about to sit exams) may experience wider consequences. Those whose life changes have been impacted by the pandemic are being referred to as the COVID-19 Generation. With COVID-19, the immediate policy response has been to protect the most vulnerable and to safeguard healthcare systems by ensuring that they are not swamped by COVID-19 cases. The longer-term impacts of this policy focus 
will ripple across the wider population. These include those with health conditions which were not diagnosed or treated because of capacity problems in healthcare systems (e.g. cancers and mental wellbeing). Economically, the pandemic has had a short-term negative impact on Gross Domestic Product (GDP) and has been responsible for destroying millions of jobs and destroying companies. It has also created new employment and business opportunities. Human behaviour, including consumer behaviour, has been transformed.

COVID-19 has transformed the relationship between place and expected rules of behaviour. Every place comes with learnt unwritten and sometimes written rules of behaviour. Prior to COVID-19, individuals could wander around a shopping district and enter shops at will. With COVID-19, the rules changed. Entering a shop required a face mask, but also required following regulations laid down by the retailer regarding the number of consumers that could be present in the shop at any one time. This often included navigating one-way systems and maintaining social distance. Religious services changed and these alterations varied by country and the regulations that were in place at any one time. Thus, during lockdowns in the UK, churches were closed, but then on reopening congregants were not permitted to sing during services (Bryson et al., 2020a). Educational provision became an exercise in managing social distance and in grouping pupils into 'social bubbles' in an attempt to minimise COVID-19 transmission.

Relationships with people, and between people, were fundamentally changed leading to wider concerns. These included a fear of the 'other' and for close human proximity. This is particularly problematic for children who then become accustomed to avoiding human interaction and to social distance. It also leads to issues regarding trust including who to include in your 'support bubble'. Wider issues of policing and denunciation also become noticeable with individuals denunciating their neighbours if they appeared not to comply with the rules. For everyone, the experience of living through the pandemic created a personal introspective journey with the pre-COVID-19 context defined as the 'life before' (and described using the past tense), pushing individuals towards diverse paths of survival and coping strategies, opening new horizons (of opportunities for some, and uncertainty and stress for others) while challenging previous knowledge, experiences, and practices.

The relationship between COVID-19, place, people, and policy was complex. It reflects individual adjustment to COVID-19 in response to policy improvisation. Households and individuals had to cope with lockdown and the imposition of major constraints on everyday living. These constraints impacted different people in different ways depending on intersectionality, location, and timing. Keyworkers, including healthcare workers had to balance working in high-risk transmission environments with everyday living. For some, this meant living temporarily away from their homes to try to prevent 
transmission to vulnerable household members. For many COVID-19 disrupted their abilities to earn a living and this was especially the case for those involved in the hospitality and entertainment industries and for those involved in face-to-face occupations. During lockdown, families with children had to cope with balancing childcare and online learning with WFH. Nevertheless, these were some of the more fortunate households as many families had to cope with being placed on furlough or unemployment combined with the death of family members and friends. Other households contained keyworkers who were working with COVID-19 patients or in high transmission occupations. Policy was developed in response to the spread of COVID-19 and as new variants emerged. Rapid policy improvisation was required based on available medical evidence and the application of social and behavioural science approaches intended to persuade people to alter their behaviour (Bavel et al., 2020). There was a tension between trying to reduce COVID-19 related deaths whilst reducing the impacts on the economy and education.

Exploring the impacts of COVID-19 on place, people, and policy involves an appreciation of the timing of impacts and adaptations combined with a focus on developing policy to support the post-pandemic recovery. In the UK and the US, the policy focus began to include a discussion on the need to 'build back better' (BBB). This concept was used by Joe Biden on 9 July 2020 when he launched his own 'build back better' recovery plan. Boris Johnson had first used this expression on 28 May 2020. This phase has been constantly repeated with reference to jobs and training in the post-COVID era. Nevertheless, the origins of this expression can be traced back to 2015 when the United Nations developed a strategy intended to reduce the risks of future shocks and disasters to people and communities (United Nations, 2015, 2017). The BBB approach focusses on "integrating disaster risk reduction measures into the restoration of physical infrastructure and societal systems" (United Nations, 2017: 6) emphasising recovery, rehabilitation, and reconstruction. The application of the BBB approach to COVID-19 recovery requires a shift in focus from the emphasis placed by the United Nations on the development of all-stakeholder national-level disaster recovery frameworks to a much more local focus. This leads us back to the ' $\mathrm{R}$ ' word - resilience.

One of the unknowns with the BBB approach is the extent to which social distancing will be replaced with social interactions in which there is no need to wear a face mask and to maintain some degree of social or physical distance. It appears likely that some form of social distancing related to the control of COVID-19 will be required even when $80 \%$ of a nation's population have been vaccinated. The impacts of COVID-19 will continue to ripple across societies and economies. There will continue to be localised outbreaks linked to cohorts who refused to participate in the vaccination programme and to business and recreational tourism. There is also the possibility of new vaccine-resilient ver- 
sions of COVID-19 forming that could require the development of a modified or even new vaccine.

Perhaps the primary challenge once COVID-19 is controlled is a return to addressing some of the primary societal challenges that will produce more Jenga Capitalism events. There are three threats here:

(1) Other pathogen outbreaks that might lead to epidemics and pandemics.

(2) Climate change will increasingly require major adaptations and mitigations. This includes the impacts of decarbonisation on everyday living combined with adaptations to some of the longer-term negative impacts of climate change.

(3) Convergence of digital systems based around the formation of a cyber-energy plexus (Bryson et al., 2021). This results in the development of complex systems in which disturbance in one part of a converged system could result in systemic failure.

\section{PAYING FOR THE PANDEMIC AND ITS INTERSECTIONAL COSTS}

COVID-19 represents a cultural inflection point; a moment or event that results in significant change that ripples across societies and economies. This type of inflection point is rare. Often an inflection point begins with a period of disruption that challenges existing conventions, routines, ways of working and living, and technologies. World Wars have represented such global inflection points associated initially with disruption and then improvisation leading to adaptations and the emergence of new routines. COVID-19 has transformed everyday living with adaptations including emotional and socio-economic survival mechanisms. These transformations reflect immediate impacts that will shape alterations to existing routines. Timescales are extremely important in exploring inflection points. These include understanding the period before the moment of inflection, during the period of change including understanding tensions between existing conventions or routines and those which are emerging in response to the drivers behind the inflection, and finally the period after the inflection point.

For COVID-19, the focus during the pandemic has been on managing the impacts on populations with a focus on minimising transmission, ensuring healthcare services can cope with demand and in mediating the economic impacts. All these interventions come with financial and social costs (Marmot et al., 2020) particularly for the most vulnerable already suffering from intersectional burdens. Over the next century, part of the national discussion will revolve around the COVID-19 generation and the longer-term impacts 
of COVID-19 on this generation. The direct immediate impacts of lockdown included unemployment, bankruptcies, poverty and deprivation, mental health issues, loneliness, domestic abuse, and hardship (Marmot et al., 2020). There are also longer-term more indirect impacts and four of these can be identified.

First, health impacts initially focussing on the longer-term impacts on people suffering from Long COVID. The term 'Long COVID' was developed as a label for people with symptoms lasting for more than 12 weeks with conditions including fatigue, breathlessness, chest pains, joint or muscle pain. There is also the need to focus on the mental health conditions arising from the pandemic episode. Part of the longer-term health impact reflects the indirect impacts on people with acute or chronic health conditions and other health conditions that were unrelated to COVID-19. During COVID-19 healthcare services were redesigned to respond rapidly to the demands placed on them by COVID-19. One consequence was a significant reduction in the use of Accident and Emergency (A\&E) services and in admissions for non-COVID related health issues. Diagnosis and treatment of other diseases and conditions was significantly delayed, and, in some cases, these delays increased mortality rates. Higher levels of poverty leading to food poverty may also lead to further diet-related health conditions.

Second, pupils and students at primary, secondary and tertiary stages have been affected by major disruptions to their education (Bryson and Andres, 2020). The impacts of these disruptions were experienced differently depending on the alignment of a complex set of factors that require further research. Nevertheless, one way of exploring these impacts is to appreciate that people are not numbers but lives. This is an important distinction and is one that sits at the centre of all forms of discrimination and inequality. This resonates with the debate on intersectionality which highlights that vulnerability, disadvantage and exclusion are explained by the intersections of multiple factors including gender, ethnicity, and class. These intersections reflect the distinction between numbers on a spreadsheet versus lives lived and the intersections produce overlapping and interdependent systems of discrimination or disadvantage and advantage (Crenshaw, 2019; Ho and Maddrell, 2020). The impacts of COVID-19 on educational outcomes may be short-term, but there will also be longer-term impacts on particular groups (those, for example, who had limited access to computers and online learning) that limit their life chances.

Third, COVID-19 destroyed jobs, working hours and created new forms of work. The "initial impact of the COVID-19 crisis on OECD labour markets $\ldots$ has been ten times larger than that observed in the first months of the 2008 global financial crisis ... total hours worked fell by $12.2 \%$ in the initial three months compared to $1.2 \%$ in 2008" (OECD, 2020: 22). According to the ILO, "there were unprecedented global employment losses in 2020 of 114 million jobs relative to 2019. In relative terms, employment losses were 
higher for women (5.0 per cent) than for men, and for young workers (8.7 per cent) than for older workers" (ILO, 2021: 2). These employment losses were highest in the Americas and lowest in Europe given the impacts of job retention schemes. The pandemic hastened the ongoing decline of bricks and mortar, or high street retailing, and accelerated the shift towards e-commerce, online retailing and WFH. Many of these changes will be linked to permanent alterations in the labour market and many businesses will never recover. COVID-19 has increased unemployment, and youth unemployment and, for some, this will result in long-term unemployment with major impacts on lifestyle and mental health. This increase in unemployment and alterations in the labour market has also impacted on the life chances of those entering the labour market for the first time.

Fourth, national economies have yet to completely recover from the 2007-08 global financial crisis (GFC). The GFC increased UK government borrowing given the requirement for an increase in government spending combined with a drop in revenue (Keep, 2020). COVID-19 has rewritten existing strategies regarding public finance. Governments have been borrowing to spend on policy initiatives intended to temper the initial impacts of COVID-19 on households and businesses. For the UK, during 2020, government expenditure increased dramatically and there was also a reduction in tax revenue. For 2020/21, the UK Office for Budget Responsibility (OBR) forecast a budget deficit of $£ 394$ billion. This represents $19 \%$ of GDP and this is the highest level since 1944-45 (Keep, 2020: 4). Around $£ 280$ billion of this deficit arises from public policy interventions intended "to tackle the virus, and to support businesses, workers and incomes" (Keep, 2020: 5). To place this in context, it is worth noting that in 2019-20, the UK public sector deficit was $£ 56$ billion or around $£ 840$ per head of population (Keep, 2020: 3). One long-term impact of COVID-19 will be an increase in direct and indirect taxation. There is perhaps another more important impact. This is the constraints imposed on public sector expenditure by the longer-term financial consequences of COVID-19. Whereas austerity was already characterising the ways in which local governments were functioning, further cuts in public funding are to be expected over the medium and longer term, leading to prioritisation amongst various competing agenda.

Paying for the pandemic cannot happen at any cost and particularly at the cost of the ongoing climate change crisis. The year 2020 was the joint hottest year ever recorded and despite a $7 \%$ fall in fossil fuel burning due to coronavirus lockdowns, heat-trapping carbon dioxide continued to build up in the 
atmosphere and this also set a new record (Carrington, 2021). The 2020 report of The Lancet Countdown on health and climate change noted that:

Harnessing the health co-benefits of climate change mitigation and adaptation will ensure the economic, social, and environmental sustainability of these efforts, while providing a framework that encourages investment in local communities and health systems and synergises with existing health challenges. (Watts et al.: 4)

The COVID-19 crisis can be seen as an opportunity. International organisations, now that vaccination programmes have commenced, are calling to reset the agenda towards the climate change emergency. Recently, the UN Secretary General, Antonio Guterres, suggested that "never before has it been so clear that we need long-term, inclusive, clean transitions to tackle the climate crisis and achieve sustainable development.... We must turn the recovery from the pandemic into a real opportunity to build a better future.... We need science, solidarity and solutions" (World Meteorological Organization, 2020: 1). Nevertheless, progress to date has been slow; significant momentum and political commitment, along with financial investment, will need to be assembled to embrace these calls in the context of pandemic recovery. The danger is that the distractions of the immediate problem will continue to marginalise policy solutions intended to address climate change.

\section{THE STRUCTURE OF THE BOOK}

In 2020, the world was turned upside down. Existing conventions were destroyed. Plans developed in 2019 and in early 2020 were shelved with households, companies, organisations, and governments entering a period of uncertainty within which the only response was based on rapid improvisation. COVID-19 has had multiple impacts on the worlds of work, everyday living, place and space, and policy. These impacts will interact with one another often in unexpected and even perverse ways. There will perhaps be some shift back to the world before COVID-19, but the world has changed, and these changes include alterations to place, people, and policy. During COVID-19, rapid adaptations occurred based on improvisation. The post-pandemic era will be one in which longer-term adjustments to the impacts of COVID-19 will continue to unfold. There are different timescales to these processes of adjustment. Some adjustments will be slow given sunk costs and path dependency linked to existing investments, for example, in the built environment of cities. Other adjustments will be extremely rapid, for example the ongoing shift towards digital money and online retailing. Some of these adjustments reflect longer-term trends. Nevertheless, it is important to appreciate that for some, the COVID-19 generation, the pandemic will have a long-term impact on their 
lives. Understanding these negative impacts and identifying policy solutions must play a central role in discussions regarding approaches to build back better. Nevertheless, it is essential that post-pandemic adjustment is positioned within the wider societal challenge that is climate change.

This book explores the evolving experiences, challenges, and reflections of the COVID-19 pandemic. The chapters in this book represent topics, themes and specialisms that have been shaped by contemporary discussions that are pertinent to the future directions of the pandemic and for understanding the wider impacts of pandemics.

In Part II of the book, the chapters explore the impacts of the COVID-19 pandemic on people, organisations, and the wider society. They highlight the increasing importance of collaboration and engagement as part of a very rapidly changing landscape. To start with, in Chapter 2, Kira Allmann explores the digital divide that has emerged during the COVID-19 pandemic. She examines three levels of digital inequality, and how they have come to the fore during the pandemic. In Chapter 3, Matthew Thomas, Tendayi Gonondo, Peter Rautenbach, Kiran Seeley, Ardita Shkurti, Angus Thomas and Holly Westlake explore the role of the university campus as a place and its relationship with the student experience during the pandemic. In Chapter 4, Megan K. Blake discusses the concept of food insecurity and how it manifested itself during the initial lockdown period. She discusses the application of a Food Ladders framework to mobilise resilience thinking as a way to evaluate food projects at the local scale as well as food landscapes (or foodscapes as she calls them). In Chapter 5, Stuart Paul Denoon-Stevens and Katrina du Toit explore the job-food-health connection in South Africa and its relation to both COVID-19 and the associated lockdown. They overview existing household strategies for accessing food and for exploring the impacts of disruptions on health. In Chapter 6, Paul Moawad and Lauren Andres review the repercussions and impacts of COVID-19 encampment mechanisms on Lebanese informal tented settlements (ITSs), on both refugees and host communities. They illustrate how the pandemic has acted as a catalyst for increased locally driven encampment and containment mechanisms and the short- and long-term impacts on both refugees and host communities. In Chapter 7, Jin-Tae Hwang problematises the Korean government's social distancing rules by highlighting the necessity of a more multi-scalar and multi-temporal approach to analysing COVID-19 landscapes. In Chapter 8, Maria Savona offers a reflection on the dichotomy between a 'new normal' and a 'new essential' (in relation to jobs and sectors). She emphasises the importance of inclusive employment and the transparent and trustworthy application of digital technologies to steer the future of digital transformation in the face of pandemics.

Part III of the book engages with the ways in which the COVID-19 pandemic changed place as well as environment. In Chapter 9, the first in this 
section, Suzanne Bartington explores the complex interrelationship between human activities and the natural environment during the COVID-19 pandemic and related public health protection measures. In her chapter, she examines examples of diverse environmental consequences including short-term reductions in pollutant emissions and the indirect impacts arising from changes to global energy systems and economic security. In Chapter 10, Ilaria Mariotti, Mina Di Marino and Mina Akhavan engage with the evolving concept of coworking spaces and the effects of the COVID-19 pandemic on them. They explore which measures can be applied by managers of these spaces to confront the during and after the pandemic situation. In Chapter 11, Andrew Davies develops a different approach as he explores how faith communities have been affected by the pandemic. He emphasises the effectiveness of the faith response to the crisis and the need for innovation for effective dissemination and community engagement. In Chapter 12, Charles Goode and Ben Rayner explore the relationship between the coronavirus and the long-term aim of digitalising the planning system. They explore the ways in which the lockdown impacted on digitalisation processes. In Chapter 13, Vincent Gruis and Aksel Ersoy discuss the immediate and structural effects of COVID-19 on housing markets. They provide an overview of the most visible short-term effects and speculate about the longer-term impacts of the pandemic on the housing sector. In Chapter 14, Frances Brill and Mike Raco assess the impacts of the COVID-19 pandemic on institutional investment flows into London's residential property market. They identify practical and structural changes that have emerged in urban property and investment markets in the face of the pandemic. Chapter 15 explores the implications of COVID-19 upon housing markets. Through bringing the countryside into the discussions, Charles Goode explores the outflow of households from cities as one response to COVID-19, and the implications of this for urban regeneration, the Green Belt and the UK government's planning reform agenda. In Chapter 16, Iain Docherty, Greg Marsden, Jillian Anable and Tom Forth review some of the changes that occurred in terms of transport and mobility during the first phase of the pandemic. They discuss the future role of travel, as well as the role cities play and their connectivity. In Chapter 17, Vida Vanchan explores global pandemic disruptions and the ways in which they impacted on the glocalisation of production networks. She highlights the increasing importance of international collaboration and co-ordination, as well as innovation and capacity building, in the face of crisis. In Chapter 18, John R. Bryson explores the impacts that COVID-19 has had on the retailing and hospitality industries. Through examples from the UK, US, France, Ireland, and India, he explores the emergence of a new geography of consumer behaviour and retailing.

In Part IV of the book, the chapters discuss the governance and policy impacts of the COVID-19 crisis. They explore the changing implications and 
reconfigurations of national policies. For instance, in Chapter 19, Steve Gulati explores the health response to the COVID-19 pandemic. He argues that the pandemic prompted rapid operational change in the UK National Health Service (NHS) including the application of different leadership approaches. In Chapter 20, Jessica Pykett and Anna Lavis outline some conceptual tools for understanding the impacts of the COVID-19 pandemic on citizenship and governance. They explore how immediate matters of life, death, urgency, and emergency might drive forward or amplify specific biopolitical forms of governance, modes of power and ethical framings of what it means to be a 'good citizen.' In Chapter 21, Nichola Lowe and Tara Vinodrai explore the influence of the pandemic on employment and its institutional responses in Canada and the United States. They argue that the COVID-19 pandemic has exposed and exacerbated existing inequalities and vulnerabilities and, at the same time, it has resulted in the adoption of new forms of work and innovation. In Chapter 22, Paul Cairney discusses the concept of evidence-informed COVID-19 policy and the UK government. Starting with a problem definition, he explores how this definition informed COVID-19 policy and resulted in unequal impacts on mortality and wellbeing. In Chapter 23, Arianna Giovannini explores the multi-level governance structures of centre-local relations in the UK. She assesses how the presence of systemic weaknesses in multi-level governance structures affected pandemic responses since the start of the coronavirus emergency in England. In Chapter 24, the final chapter in this section of the book, Pere Suau-Sanchez, Augusto Voltes-Dorta, Natàlia Cugueró-Escofet and Keith J. Mason investigate the impact of COVID-19 on commercial aviation. By analysing supply and demand datasets, and fleet status changes, this chapter reveals the intense impacts that COVID-19 has had on the aviation market and its wider ecosystem. The final chapter, Chapter 25, develops a conceptual framework for exploring pandemics that highlights the importance of exploring pandemic preparedness, responsiveness, and recovery.

Each chapter provides a different lens on understanding the impacts of the COVID-19 pandemic during 2020. This was a year in which everyday living was transformed. This transformation included the destruction of some existing jobs and the creation of new employment opportunities. This included transferring education from schools and universities to homes and to the world of online education. It included rapid improvisation in healthcare provision, the development of new vaccines and in government policy intended to facilitate everyday living during a pandemic. 


\section{REFERENCES}

Agnew, S. and Hickson S. (2012), 'Using online assessment to replace invigilated assessment in times of a natural disaster: Are some online assessment conditions better than others?', Journal of Open, Flexible, and Distance Learning, 16(1): 1-13.

Andres, L. (2020), 'The importance of temporary urbanism in deconstructing cities and shaping the post-pandemic city research agenda', in Topuzovski, T. (ed.), Horizons: Selected Lectures at Museum of Contemporary Art Skopje 2018-2019, Museum of Contemporary Art: Skopje, pp. 83-92.

Anguelovski, I., Brand, A.L., Connolly, J.J.T., Corbera, E., Kotsila, P. et al. (2020), 'Expanding the boundaries of justice in urban greening scholarship: Toward an emancipatory, antisubordination, intersectional, and relational approach', Annals of the American Association of Geographers, 110(6): 1743-1769.

Bavel, J.J.V., Baicker, K., Boggio, P.S., Capraro, V., Cichocka, A. et al. (2020), 'Using social and behavioural science to support COVID-19 pandemic response', Nature Human Behaviour, 4: 460-471.

BBC (2020), 'Covid-19 vaccine: First person receives Pfizer jab in UK', accessed 26 January 2021, at https://www.bbc.co.uk/news/uk-55227325.

Beck, U. (1992), Risk Society: Towards a New Modernity, London: Sage.

Bryson, J.R. (2021), 'Reading manufacturing firms: Lost geographies of value/risk and the emergence of Jenga Capitalism', in Bryson, J.R., Billing, C., Graves, W. and Yeung, G. (eds), A Research Agenda for Manufacturing Industries in the Global Economy, Edward Elgar Publishing: Cheltenham, UK and Northampton, MA, USA, in press.

Bryson, J.R. and Andres, L. (2020), 'Covid-19 and rapid adoption and improvisation of online teaching: Curating resources for extensive versus intensive online learning experiences', Journal of Geography in Higher Education, DOI: 10.1080/03098265.2020.1807478.

Bryson, J.R., Andres, L. and Davies, A. (2020a), 'Covid-19, virtual church services and a new temporary geography of home', Tijdschrift voor Economische en Sociale Geografie, https://doi.org/10.1111/tesg.12436.

Bryson, J.R., Kalafsky, R.V. and Vanchan, V. (2021), 'Ordinary cities, extraordinary geographies: Parallax dimensions, interpolations and the scale question', in Bryson, J.R., Kalafsky, R.V. and Vanchan, V. (eds), Ordinary Cities, Extraordinary Geographies: People, Place and Space, Edward Elgar Publishing: Cheltenham, UK and Northampton, MA, USA, in press.

Bryson, J.R., Sundbo, J., Fuglsang, L. and Daniels, P. (2020b), Service Management: Theory and Practice, Palgrave Macmillan: London.

Bryson, J.R. and Vanchan, V. (2020), 'COVID-19 and alternative conceptualisations of value and risk in GPN research', Tijds. voor econ. en Soc. Geog., 111: 530-542.

Carrington, D. (2021), 'Climate crisis: 2020 was joint hottest year ever recorded', The Guardian, 8 January 2021, accessed on 26 April 2021, at https://www.theguardian .com/environment/2021/jan/08/climate-crisis-experts-2020-joint-hottest-year-ever -recorded.

Centers for Disease Control and Prevention (2020), 'Past Pandemics', accessed 25 January 2021, at https://www.cdc.gov/flu/pandemic-resources/basics/past -pandemics.html.

Collings, D.A., Gerrard, J.A. and Garrill A. (2019), 'Shaking up biology: Our experiences teaching cell biology and biochemistry to a first year undergraduate 
class through the Canterbury (New Zealand) earthquakes', Journal of Biological Education, 53(3): 236-249.

Crenshaw, K. (2019), On Intersectionality: Essential Writings, The New Press: New York.

Cyert, R.M. and March, J.G. (2001), A Behavioural Theory of the Firm, Blackwell: Oxford.

Day, T. (2015), 'Academic continuity: Staying true to teaching values and objectives in the face of course interruptions', Teaching and Learning Inquiry, 3(1): 75-89.

du Plessis, L., McCrone, J.T., Zarebski, A.E., Hill, V., Ruis, C. et al. (2021), 'Establishment \& lineage dynamics of the SARS-CoV-2 epidemic in the UK', Science, 8 January: eabf2946, DOI: 10.1126/science.abf2946.

Gambrel, P.A. and Cianci, R. (2003), 'Maslow's hierarchy of needs: Does it apply in a collectivist culture', The Journal of Applied Management and Entrepreneurship, 8(2): 143-161.

Gardner, E. and Bryson, J.R. (2020), 'The dark side of the industrialisation of accountancy: Innovation, commoditization, colonization and competitiveness', Industry and Innovation, 28(1): 42-57.

Gates, B. (2018), 'Innovation for pandemics', The New England Journal of Medicine, 378: 2057-2060, DOI: 10.1056/NEJMp1806283.

GHRF Commission (2016), 'The neglected dimension of global security: A framework to counter infectious disease crises', Commission on a Global Health Risk Framework for the Future, US National Academy of Medicine: Washington DC, http://nam.edu/GHRFreport, DOI: 10.17226/21891.

Giddens, A. (1998), The Third Way: The Renewal of Social Democracy, Polity Press: Cambridge, UK.

Giddens, A. (1999), 'Risk and responsibility', Modern Law Review, 62(1): 1-10.

Hall, P.A. and Thelen, K. (2008), 'Institutional change in varieties of capitalism', Socio-Economic Review, 7(1): 7-34.

Ho, E.L. and Maddrell, A. (2020), 'Intolerable intersectional burdens: A COVID-19 research agenda for social and cultural geographies', Social \& Cultural Geography, DOI: $10.1080 / 14649365.2020 .1837215$.

Horton, R. (2020), The COVID-19 Catastrophe: What's Gone Wrong and How to Stop it Happening Again, Polity Press: Cambridge

ILO (2021), 'ILO Monitor: COVID-19 and the world of work', International Labour Organization, accessed 26 April 2021, at https:/www.ilo.org/wcmsp5/groups/ public/@dgreports/@dcomm/documents/briefingnote/wcms_767028.pdf.

Iyengar, K.P. and Jain, V.K. (2020), 'COVID-19 and the plight of migrants in India', Postgraduate Medical Journal, Published Online First: 12 August 2020. DOI: 10.1136/postgradmedj-2020-138454.

Jarvis, D.S.L. (2007), 'Risk, globalisation and the state: A critical appraisal of Ulrich Beck and the world risk society thesis', Global Society, 21(1): 23-46.

Johns Hopkins (2021), Mortality Analysis, Johns Hopkins Coronavirus Centre, accessed 1 February 2021, at https://coronavirus.jhu.edu/data/mortality.

Keep, M. (2020), The Budget Deficit, House of Commons Library, Briefing Paper 06167.

Kucharski, A. (2020), The Rules of Contagion: Why Things Spread - and Why They Stop, Profile Books: London.

Lederberg, J., Shope, R.E. and Oaks, S.C. (eds) (1992), Emerging Infections: Microbial Threats to Health in the United States, Institute of Medicine (US) Committee on 
Emerging Microbial Threats to Health: Washington (DC), accessed 23 December 2020, at https://www.ncbi.nlm.nih.gov/books/NBK234860/.

MacKenzie, D. (2020), COVID-19: The Pandemic that Never Should Have Happened and How to Stop the Next One, The Bridge Street Press: London.

Mackey, J., Gilmore, F.., Dabner, N., Breeze, D. and Buckley, P. (2012), 'Blended learning for academic resilience in times of disaster or crisis', MERLOT Journal of Online Learning and Teaching, 8(2): 122-35.

Marmot, M., Alle, J., Goldblatt, P., Herd, E., and Morrison, J. (2020), Build Back Fairer: The COVID-19 Marmot Review, Institute of Health Equity: London.

McIntyre, L. (2018) Post-Truth, MIT Press: Cambridge.

Mo, Pak. (2007), 'The nature of Chinese collective values: Formation and evolution', International Journal of Chinese Culture and Management, 1: 108-125, 10.1504/ IJCCM.2007.016171.

Murray, Y. (2021), 'Draconian measures help China suppress Covid-19', RTE News, accessed 1 February 2021, at https://www.rte.ie/news/coronavirus/2021/0131/ 1194057-china-covid-19-containment/.

OECD (2020), OECD Employment Outlook 2020: Worker Security and the COVID-19 Crisis, OECD Publishing: Paris, https://doi.org/10.1787/1686c758-en.

Perrow, Charles (1984), Normal Accidents: Living With High Risk Technologies, Princeton University Press: Princeton, NJ.

Perrow, Charles (2007), The Next Catastrophe: Reducing Our Vulnerabilities to Natural, Industrial, and Terrorist Disasters, Princeton University Press: Princeton, NJ.

Perrow, Charles and Guillén, Mauro F. (1990), The AIDS Disaster: The Failure of Organizations in New York and the Nation, Yale University Press: New Haven, CT.

ProMed (2021), ProMED International Society for Infectious Diseases, accessed 26 January 2021 at https://promedmail.org/.

Salder, J. and Bryson, J.R. (2019), 'Placing entrepreneurship and firming small town economies: Manufacturing firms, adaptive embeddedness, survival and linked enterprise structures', Entrepreneurship \& Regional Development, 31(9-10): 806-825.

Santibañez, S., Fiore, A.E., Merlin, T.L. and Redd, S. (2009), 'A primer on strategies for prevention and control of seasonal and pandemic influenza', American Journal of Public Health, 99(S2): S216-S224.

Sørensen, M.P. (2002), 'Interview med Ulrich Beck', Slagmark, 34: 125-144.

Sørensen, M.P. (2018), 'Ulrich Beck: Exploring and contesting risk', Journal of Risk Research, 21(1): 6-16.

Stedman, G. (2021), '2020 retail trends: Lipstick sales drop, casual wear soars', accessed 4 January 2021, at https://www.rte.ie/news/business/2020/1222/1185929 -2020-retail-trends-lipstick-sales-fall-casual-wear-up/.

Stipek D. (1998), 'Differences between Americans and Chinese in the circumstances evoking pride, shame, and guilt', Journal of Cross-Cultural Psychology, 29(5): 616-629.

Tan, W.J. and Enderwick, P. (2006), 'Managing threats in the global era: The impact and response to SARS', Thunderbird International Business Review, 48: 515-536.

The Lancet (2020), 'India under COVID-19 lockdown', Lancet, 395: 1315. DOI: 10.1016/S0140-6736(20)30938-7.

United Nations (2015), Sendai Framework for Disaster Risk Reduction 2015-2030, United Nations.

United Nations (2017), Build Back Better in Recovery, Rehabilitation and Reconstruction, United Nations Office for Disaster Risk Reduction. 
Watts, N., Aman, M., Arnel, N., Ayeb-Karlsso, S., Beagley, J. et al. (2020), 'The 2020 report of the Lancet Countdown on health and climate change: Responding to converging crises', Lancet, 397: 129-170, https://doi.org/10.1016/ S0140-6736(20)32290-X.

WHO (2020), 'Avoid the three Cs', accessed 4 January 2020, at https://www.who.int/ brunei/news/infographics---english.

World Meteorological Organization (WMO) (2020), United in Science 2020 - UN Climate Report. 10.13140/RG.2.2.12801.28004, accessed 26 April 2021, at public .wmo.int/en/resources/united_in_science.

Young, J.R. (2009), 'In case of emergency, break tradition - teach online, The Chronicle of Higher Education, August 17, accessed 26 January 2021, at https:// www.chronicle.com/article/in-case-of-emergency-break-tradition-teach-online/.

Žižek, S. (2020), COVID-19 Shakes the World, Polity Press: New York. 